\title{
Detailed Chemical Kinetic Reaction Mechanisms for Autoignition of Isomers of Heptane Under Rapid Compression
}

C.K. Westbrook, W.J. Pitz, J.E. Boercker, H.J. Curran, J.F. Griffiths, C. Mohamed, M. Ribaucour

This article was submitted to $29^{\text {th }}$ International Symposium on Combustion, Sapporo, Japan, July 21-26, 2002 


\section{DISCLAIMER}

This document was prepared as an account of work sponsored by an agency of the United States Government. Neither the United States Government nor the University of California nor any of their employees, makes any warranty, express or implied, or assumes any legal liability or responsibility for the accuracy, completeness, or usefulness of any information, apparatus, product, or process disclosed, or represents that its use would not infringe privately owned rights. Reference herein to any specific commercial product, process, or service by trade name, trademark, manufacturer, or otherwise, does not necessarily constitute or imply its endorsement, recommendation, or favoring by the United States Government or the University of California. The views and opinions of authors expressed herein do not necessarily state or reflect those of the United States Government or the University of California, and shall not be used for advertising or product endorsement purposes.

This is a preprint of a paper intended for publication in a journal or proceedings. Since changes may be made before publication, this preprint is made available with the understanding that it will not be cited or reproduced without the permission of the author.

This report has been reproduced directly from the best available copy.

Available electronically at http://www.doc.gov/bridge

Available for a processing fee to U.S. Department of Energy And its contractors in paper from

U.S. Department of Energy

Office of Scientific and Technical Information

$$
\text { P.O. Box } 62
$$

Oak Ridge, TN 37831-0062

Telephone: (865) 576-8401

Facsimile: (865) 576-5728

E-mail: reports@adonis.osti.gov

Available for the sale to the public from

U.S. Department of Commerce

National Technical Information Service 5285 Port Royal Road Springfield, VA 22161

Telephone: (800) 553-6847

Facsimile: (703) 605-6900

E-mail: orders@ntis.fedworld.gov

Online ordering: http://www.ntis.gov/ordering.htm

\section{OR}

Lawrence Livermore National Laboratory

Technical Information Department's Digital Library

http://www.llnl.gov/tid/Library.html 


\title{
Detailed Chemical Kinetic Reaction Mechanisms for Autoignition of Isomers of Heptane Under Rapid Compression
}

\author{
C. K. Westbrook, W. J. Pitz, J. E. Boercker \\ Lawrence Livermore National Laboratory, Livermore, CA USA \\ H. J. Curran \\ Galway-Mayo Institute, Galway, Ireland \\ J. F. Griffiths, C. Mohamed* \\ University of Leeds, Leeds, United Kingdom \\ M. Ribaucour \\ Université des Sciences et Technologies de Lille \\ Villeneuve d"Ascq, France
}

\begin{abstract}
Detailed chemical kinetic reaction mechanisms are developed for combustion of

all nine isomers of heptane $\left(\mathrm{C}_{7} \mathrm{H}_{16}\right)$, and these mechanisms are tested by simulating autoignition of each isomer under rapid compression machine conditions. The reaction mechanisms focus on the manner in which the molecular structure of each isomer determines the rates and product distributions of possible classes of reactions. The reaction pathways emphasize the importance of alkylperoxy radical isomerizations and addition reactions of molecular oxygen to alkyl and hydroperoxyalkyl radicals. A new reaction group has been added to past models, in which hydroperoxyalkyl radicals that originated with abstraction of an $\mathrm{H}$ atom from a tertiary site in the parent heptane molecule are assigned new reaction sequences involving additional internal $\mathrm{H}$ atom abstractions not previously allowed. This process accelerates autoignition in fuels with tertiary $\mathrm{C}-\mathrm{H}$ bonds in the parent fuel. In addition, the rates of hydroperoxyalkylperoxy radical isomerization reactions have all been reduced so that they are now equal to rates of analogous alkylperoxy radical isomerizations, significantly improving agreement between computed and experimental ignition delay times in the rapid compression machine. Computed ignition delay times agree well with experimental results in the few cases where experiments have been carried out for specific heptane isomers, and predictive model calculations are reported for the remaining isomers. The computed results fall into three general groups; the first consists of the most reactive isomers, including $n$ heptane, 2-methyl hexane and 3-methyl hexane. The second group consists of the least reactive isomers, including 2,2-dimethyl pentane, 3,3-dimethyl pentane, 2,3-dimethyl pentane, 2,4-dimethyl pentane and 2,2,3-trimethyl butane. The remaining isomer, 3-ethyl pentane, was observed computationally to have an intermediate level of reactivity. These observations are generally consistent with
\end{abstract}


knocking tendencies of these isomers, as measured by octane ratings, although the correlations are only approximate.

* Current affiliation: Combustion Systems Engineering, Rolls Royce, Derby, UK 


\section{Introduction}

Hydrocarbon ignition plays a major role in many practical combustion systems, and experimental studies in systems such as shock tubes, detonations, pulse combustors, rapid compression machines, and internal combustion engines have all assisted in the development of detailed chemical kinetic ignition models to describe those systems. In turn, detailed kinetic modeling [1] has helped provide better understanding of these phenomena that is extremely valuable in improving the performance and emissions of practical energy conversion systems.

Experiments and kinetic modeling studies with rapid compression machines (RCM) have been particularly useful in providing both qualitative and quantitative insights into fundamental chemistry of hydrocarbon ignition [2-7], ignition in the RCM, engine knock [8], and ignition in diesel [9] and homogeneous charge compression ignition ( $\mathrm{HCCl}$ [1] engines. The RCM studies are relevant because "end gases" in spark-ignited engines and igniting fuel/air mixtures in diesel and $\mathrm{HCCl}$ engines all pass through the same range of temperatures as reactants being compressed in the RCM, and the kinetic reaction pathways are the same in both types of combustion systems [1].

In this study, detailed kinetic reaction mechanisms are developed for oxidation of the isomers of heptane $\left(\mathrm{C}_{7} \mathrm{H}_{16}\right)$ and applied to calculating autoignition under RCM conditions. Computed results are compared with available experimental data for several of the isomers $[2,6]$, while the results for the remaining fuels represent kinetic model predictions. This choice of fuels is 
motivated by three specific goals. First, hydrocarbon fuel molecular structure has long been observed to have a considerable influence on ignition rates [10], and experimental and kinetic modeling studies of ignition of smaller paraffin fuels [5, 11-13] have explored these factors. The isomers of heptane provide an unusually wide range of ignition rates at high temperatures [14] and in engines, as measured by the range in Research Octane Number (RON) from 0 for $n$ heptane to 112 for 2,2,3-trimethyl butane, as shown in Table 1. Second, these fuels can help construct surrogate multicomponent species mixtures to represent gasoline, diesel or other practical combustion fuels. Finally, these detailed models provide a wide range of validated reaction mechanisms that can test proposed automatic mechanism generation and systematic mechanism reduction techniques.

\section{Rapid Compression Machine}

Simulations of autoignition of heptane isomers are carried out under conditions encountered in the RCM. These computations utilized the operating parameters of the Leeds University RCM, from which a limited amount of experimental data for autoignition were available for some of the heptane isomers. While no new RCM experiments were carried out for this study, some results have been published for n-heptane [6] and for 2,4-dimethyl pentane and 3,3-dimethyl pentane, over a rather wide range of compression temperatures, along with a limited range of results for 2-methyl hexane, 2,2-dimethyl pentane, and 2,3-dimethyl pentane [2]. 
Details of the operation and data acquisition in the RCM are provided in earlier papers $[2,6]$. The present computations are numerical "experiments" which simulate single-stroke compression of stoichiometric heptane/oxygen mixtures diluted by mixtures of argon and nitrogen. The diluent was $79 \%$ of the $\mathrm{O}_{2}+$ diluent mixture, so when the diluent consisted entirely of $\mathrm{N}_{2}$, the reactant mixtures were stoichiometric in air. Compressed gas temperatures were varied by changing proportions of inert diluents $\left(\mathrm{N}_{2}, \mathrm{Ar}\right)$. Changes in inert composition alter the ratio of specific heats of the reactants and therefore the temperature on compression between $685 \mathrm{~K}$ to $868 \mathrm{~K}$. The duration of the compression stroke is $22 \mathrm{msec}$, and ignition delay is measured from the end of the compression stroke. Heat losses during compression and after top dead center (TDC) are included in the model, using a distributed heat loss term, assuming that the combustion chamber is uniform in temperature and composition at any given time. Heat losses to combustion chamber walls were estimated by matching experimental and computed pressure histories for nonreactive gas mixtures. Griffiths et al. [15] used 3D fluid mechanics modeling to assess the errors involved in a homogeneous reactor assumption. Their study indicated that heat loss rates were quite variable over the combustion chamber surfaces during the compression stroke, due to variations in fluid flow rates and turbulence levels at different locations in the chamber. After TDC, turbulence levels decay rapidly, and the overall heat loss rates are reduced. These calculations show that the assumption of a homogeneous, averaged rate of heat loss is not a particularly 
good approximation and that local ignition behavior will often be different from average behavior.

Another issue addressed in recent studies [6] concerns the possibility that significant heat release can occur prior to the end of the RCM compression stroke. In the present family of heptane isomers, such conditions were observed computationally only in the results for n-heptane.

\section{Kinetic Mechanisms}

The high temperature detailed submechanisms for the heptanes were taken from a recent study [14] without modification. The submechanisms for smaller, $C_{1}-C_{6}$ hydrocarbons were taken from previous studies $[5,12]$.

The major kinetic features for low temperature hydrocarbon oxidation have become quite familiar. The submodel for higher temperatures $(T \geq 950 \mathrm{~K})$ results from thermal decomposition of alkyl radicals produced from $\mathrm{H}$ atom abstraction from each fuel. At lower temperatures, alkyl radicals $\mathrm{R}$ add to molecular oxygen to produce alkylperoxides $\mathrm{RO}_{2}$, which then initiate an extended series of elementary reactions that lead ultimately to chain branching. As the reaction temperature increases above about $900 \mathrm{~K}$, the $\mathrm{RO}_{2}$ decomposes thermally, shutting off the low temperature chain branching reaction pathways and reducing the overall rate of reaction, producing the negative temperature coefficient (NTC) of reaction that persists until further increases in temperature lead to new chain branching reaction pathways. 
The many reactions in this regime have been discussed in considerable detail $[8,16,17]$ and the kinetic details have been described in detail recently for n-heptane [18] and iso-octane [19]. At each step, rates and product distributions of elementary reactions depend on the detailed structure of the fuel. Addition and decomposition rates of $\mathrm{R}+\mathrm{O}_{2}=\mathrm{RO}_{2}$ depend on whether the $\mathrm{O}_{2}$ is bound at a primary, secondary, or tertiary site in the alkyl radical. The resulting alkylperoxy radical isomerization reaction $\mathrm{RO}_{2}=. \mathrm{QOOH}$, where. $\mathrm{QOOH}$ represents a hydroperoxyalkyl radical, occurs via internal abstraction of an $\mathrm{H}$ atom, with rates that vary with the type of $\mathrm{C}-\mathrm{H}$ bond being broken and the size of the intermediate transition state ring size. Rates of alkylperoxy isomerizations have been evaluated from experimental and theoretical studies [17,20-22], while kinetic modeling evaluations have also been used to estimate these rates $[8,11]$, but their rates as functions of temperature and $\mathrm{RO}_{2}$ structure remain somewhat uncertain.

Several product families of .QOOH decomposition are possible, depending on the structure of the .QOOH species. When the radical site is adjacent to the $\mathrm{OOH}$ group, possible products are alkene+HO 2 , and when the radical site is $\beta$ to the $\mathrm{OOH}$ group, possible products are alkene+aldehyde $+\mathrm{OH}$. All of the .QOOH species can also produce cyclic ethers $+\mathrm{OH}$, at varying rates depending on the number of $\mathrm{C}$ atoms in the product cyclic ether. 
For all .QOOH species, a second $\mathrm{O}_{2}$ addition can occur, again with addition and decomposition rates dependent on the type of $\mathrm{C}-\mathrm{O}$ bond, and the resulting $\mathrm{O}_{2} \mathrm{QOOH}$ can isomerize internally, at rates depending on the structure of the species. These "second round" of isomerization reactions have been even less studied than their $\mathrm{RO}_{2}$ counterparts noted above, and their rates are even less certain. The $\mathrm{O}_{2} \mathrm{QOOH}$ isomerization rates have sometimes been assumed to depend on transition state ring strain energy and $\mathrm{C}-\mathrm{H}$ bond strength in exactly the same manner as $\mathrm{RO}_{2}$ isomerizations, assuming the bond strength is about $3 \mathrm{kcal} / \mathrm{mol}$ less in $\mathrm{O}_{2} \mathrm{QOOH}$ than in the corresponding $\mathrm{RO}_{2}$ radical due to the presence of the $\mathrm{OOH}$ group attached to the same $\mathrm{C}$ atom from which the $\mathrm{H}$ is being abstracted.

All of these variabilities produce different overall rates of reaction for each isomer of heptane. Bonds at tertiary sites in a hydrocarbon are weaker than those at secondary sites, which are weaker than those at primary sites. Thus $\mathrm{H}$ atoms at tertiary sites are easiest to abstract, which then encourages $\mathrm{O}_{2}$ addition at tertiary sites. However, these $\mathrm{C}-\mathrm{O}$ bonds are relatively weak, so the $\mathrm{O}_{2}$ will be lost to dissociation at lower temperatures than $\mathrm{O}_{2}$ added to secondary and primary sites. Similarly, ring strain energy barriers depend on sizes of transition state rings, again affecting the ignition rate of each isomer. 
There is insufficient space available here for the entire reaction mechanisms, but they will be available on a public Web page [23] in formats suitable for kinetic programs. In the present models, the core $C_{1}-C_{6}$ submechanism includes 3397 elementary reversible reactions and 781 distinct chemical species. Submodels for each heptane isomers include approximately 200 additional species and 500 more reactions.

\section{RCM Simulations}

Variations in the $\mathrm{N}_{2} / \mathrm{Ar}$ ratio produce compressed reactant temperatures between $685 \mathrm{~K}$ and $868 \mathrm{~K}$ for each heptane isomer. The simulations included the entire compression stroke and the post-compression constant volume period. Computed results are shown in Figure 1 for 2-methyl hexane, with experimental results [2] for the same fuel and for 2-methyl pentane. For the limited range over which 2-methyl hexane experiments were reported, agreement between computed and measured ignition delays is excellent. Both computed and experimental results are distinctly more reactive than the related hexane isomer, 2-methyl pentane, consistent with the larger RON value for 2-methyl pentane, $\mathrm{RON}=73$, compared to 42 for 2 -methyl hexane. The curves for all three fuels show the familiar S-shape associated with the NTC region.

The results of Fig. 1 suggest that the heat loss model is quite reasonable for these very reactive fuels with their short ignition delay times. During compression, heat losses to chamber walls are fairly rapid, due to turbulent fluid 
flows in the chamber. Over this period, the distributed heat loss uses a characteristic time of 50 milliseconds in the simulations using the HCT computer model [24]. After TDC, the turbulence decays rapidly, and the model uses a characteristic heat transfer time of 200 milliseconds.

A second series of comparisons between computed and experimentally measured ignition delays are shown for 2,4-dimethyl pentane in Figure 2. Griffiths et al. [2] reported results for 3,3-dimethyl pentane that are very similar to those for 2,4-dimethyl pentane in Fig. 2, and both have nearly the same RON values ( 81 vs. 83 ). For compression temperatures above $800 \mathrm{~K}$, both the computed and experimental values show the same temperature dependence as shown in Fig. 1 for 2-methyl hexane. However, for both fuels, the experiments indicated a region of temperature around $750 \mathrm{~K}$ where no ignition was observed, in contrast to the computed results, for which the model indicates a conventional S-shape and NTC behavior. Interestingly, in an unpublished study some years ago [25], the RCM facilities at Leeds University and at the Universite de Lille carried out parallel studies of ignition of n-heptane and iso-octane, and for the least reactive fuels including iso-octane, the Leeds $\mathrm{RCM}$ found a region of temperature in which no ignition was observed, qualitatively similar to the experimental results in Fig. 2. The Lille RCM, with its slower compression stroke (60 ms) and somewhat different geometry, did not show the same type of behavior, but rather a smooth curve more like the computed results of Fig. 2 . More thorough multidimensional fluid dynamics simulations of the Leeds experiments [15] demonstrated that the details of the heat transfer in that RCM 
are quite complex, both with respect to the geometry and over the time history of the experiment, and it is reasonable to conclude that these effects become more influential for the isomers with the longest ignition delays, with more time for heat to be lost and thereby delay the ignition further. Such effects cannot be reproduced in the present homogeneous computational "reactor", even with its distributed heat loss submodel.

These observations are reinforced by the results in Figure 3 for 2,2dimethyl pentane $(\mathrm{RON}=93)$, where the experimental results diverge even more rapidly and at higher compression temperatures than the lower RON heptanes in Figs. 1 and 2.

Both 2,2-dimethyl pentane and 2,4-dimethyl pentane are related to 2methyl pentane through substitution of a methyl group at either the 2 or the 4 location. Both modifications increase the computed ignition delay of 2-methyl pentane by slightly more than 20 ms over most of the observed temperature range. Both accomplish this increase by removing the long chain of secondary $\mathrm{C}-\mathrm{H}$ groups and their associated rapid $\mathrm{H}$ atom abstraction reactions and low energy barrier $\mathrm{RO}_{2}$ isomerization reaction pathways.

During the numerical simulations, it became clear that there were two major deficiencies in the kinetic models for the heptane isomers. Both problems involved rates of isomerization of $\mathrm{O}_{2} \mathrm{QOOH}$ radical species. The first problem appeared when computed ignition delay times for 2,4-dimethyl pentane, 2,3dimethyl pentane, 2,2-dimethyl pentane and 2,2,3-trimethyl butane were much 
too long when compared with experimental results as in Figs. 2 and 3. In fact, for most of the experimental range of compression temperatures, these less reactive isomers were not predicted to ignite at all. It became clear that $\mathrm{O}_{2} \mathrm{QOOH}$ isomerization reactions involving the tertiary $\mathrm{C}-\mathrm{H}$ sites in these fuel molecules were more significant than in previous modeling studies with smaller fuels $[5,8,12]$.

Earlier reaction mechanisms assumed that while tertiary $\mathrm{RO}_{2}$ radicals could isomerize, the $\mathrm{O}_{2} \mathrm{QOOH}$ species formed subsequently had no reactive pathways available except to dissociate back to $\mathrm{O}_{2}+\mathrm{QOOH}$. We had assumed that the preferred second isomerization must take place where the original $\mathrm{OOH}$ had bonded. This assumption was based on computation of the lower enthalpy of reaction $\left(\Delta \mathrm{H}_{\mathrm{rxn}}\right)$ for an isomerization reaction involving an $\mathrm{H}$ atom on a carbon with a substituted $\mathrm{OOH}$ group, versus an $\mathrm{H}$ atom on a carbon without such a group. The lower enthalpy of reaction reduces the activation energy of the reaction since the reaction is less "up-hill" and also causes a corresponding change in the abstraction activation energy $\left(\mathrm{Ea}_{\mathrm{ABST}}\right)$ through an Evans-Polanyi relationship of EaABST vs. $\Delta H_{r x n}[26]$. The $\Delta H_{r x n}$ were computed from species enthalpies based on group additivity, and the average reduction in activation energy for the second isomerization was calculated to be $3 \mathrm{kcal} / \mathrm{mole}$.

However, when the original $\mathrm{H}$ atom abstraction in the parent fuel occurs at a tertiary $\mathrm{C}-\mathrm{H}$ site, there is no second $\mathrm{H}$ atom for the second internal $\mathrm{H}$ atom 
abstraction in $\mathrm{O}_{2} \mathrm{QOOH}$, thereby making those $\mathrm{O}_{2} \mathrm{QOOH}$ radicals completely unreactive, except to dissociate. To correct this oversight, alternative internal $\mathrm{H}$ atom abstractions in these radicals were included in the revised detailed kinetic mechanisms, with rate expressions equal to those internal $\mathrm{H}$ atom abstractions in $\mathrm{RO}_{2}$ with the same ring strain and bond energy contributions. With the additional chain branching provided by these reaction pathways, the computed ignition rates for these isomers became much faster and in much better agreement with the experimental results.

The second major modification to the reaction mechanisms for these isomers was motivated by the two diamond-shaped points in Fig. 3, which were computed using the previous mechanisms. Note that for this fuel, there are no tertiary $\mathrm{C}-\mathrm{H}$ bonds, so model corrections for tertiary site isomerizations in $\mathrm{O}_{2} \mathrm{QOOH}$ radicals were irrelevant. Careful analysis of the computed results for fuels such as those in Figs. 2 and 3, as well as for 3,3-dimethyl pentane and then eventually for the other isomers led to identification of a kinetic feature we had not previously recognized, as follows.

For most of the heptane isomers, the reactions

$$
\mathrm{QOOH}+\mathrm{O}_{2}=\mathrm{O}_{2} \mathrm{QOOH}
$$

quickly become strongly equilibrated. Subsequent isomerization reactions proceed very slowly, and in most cases the rate of isomerization is less than 0.01 times the dissociation rate back to $\mathrm{QOOH}+\mathrm{O}_{2}$. However, for the fastest 
isomerizations, the model predicted rates that were as much as $10-20 \%$ of the dissociation rates. This resulted in extremely fast rates of ignition, since the products of isomerization include two $\mathrm{OH}$ radicals and other very reactive intermediates and radical species, providing large rates of chain branching.

Systematic sensitivity analyses indicated that the parameters most responsible for these erroneously large rates of reaction were the activation energies for the $\mathrm{O}_{2} \mathrm{QOOH}$ isomerizations which, as noted, had been assumed to be smaller by $3 \mathrm{kcal} / \mathrm{mol}$ than the same reactions in $\mathrm{RO}_{2}$ radicals. When these activation energies were restored to the same values as in corresponding $\mathrm{RO}_{2}$ radicals, the computed results were in best overall agreement with the experimental results. In addition, as shown next, the relative computed ignition behaviors of all of the heptane isomers were found to be most consistent with other low temperature ignition data when the isomerization activation energies were restored to the same values as in the corresponding $\mathrm{RO}_{2}$ species reactions. We believe that this is an issue that merits further theoretical and experimental study. It is possible that the bond energies for these species are incorrect, or perhaps the ring strain or A-factors for these isomerizations are not correct, or that there are additional kinetic factors that are not being included in the model formulations. Of course, in kinetic mechanisms of the present complexity, there are many alternative explanations for such effects, but the 
absence of some of these factors in models of smaller fuel molecules suggests that some new features are beginning to appear for larger fuel molecules.

Computed results for all nine heptane isomers are summarized in Figure 4, using the reaction mechanisms modified as already described to account for changes in rate expressions for isomerizations of $\mathrm{O}_{2} \mathrm{QOOH}$ species. All of the results show the familiar S-shapes, with the exception of n-heptane, which reacts to a significant degree during the compression stroke as observed previously [6]. The overall ordering of the isomers is roughly related to their RON values, with the most reactive isomers being $n$-heptane $(\mathrm{RON}=0)$, 2-methyl hexane $(\mathrm{RON}=42)$ and 3-methyl hexane $(\mathrm{RON}=52)$. There is an intermediate range where 3-ethyl pentane $(\mathrm{RON}=65)$ is the only isomer, and a third, clearly less reactive group of isomers, including 2,2-dimethyl pentane ( $\mathrm{RON}=93), 3,3$ dimethyl pentane ( $R O N=81$ ), 2,4-dimethyl pentane ( $R O N=83$ ), 2,2,3-trimethyl butane (RON=112), and 2,3-dimethyl pentane ( $R O N=91)$ with relatively little difference between them, except for 2,3-dimethyl pentane, which is the least reactive.

Griffiths et al. [2] studied the experimental results for autoignition of some of these isomers, together with other fuels and fuel mixtures, in an attempt to correlate these experiments with knocking tendency, focusing on conditions near $900 \mathrm{~K}$, which is close to the temperature where the actual ignition occurs for each of these fuels [1]. Fig. 4 shows that above $850 \mathrm{~K}$ all of the computed results are very similar, especially for the higher octane fuels, making it difficult to make comparisons reliably. However, even at lower temperatures below 750K, 
although results for the different fuels are better differentiated than at the higher values, correlation between RON and ignition time is only qualitative. Given the complexity of the mechanisms and the uncertainties remaining in some of the important classes of reactions and rates, it is unrealistic to assert that this level of correlation is due to inadequacies in the kinetic mechanisms, to uncertainties in RCM experimental results, or to other factors. In fact, the most likely explanation is that knocking tendency is measured in an operating spark-ignition engine, not an RCM, and while the RCM is a better simulation of end gas evolution than most other laboratory experiments, it is still sufficiently different from a real engine that one cannot expect it to provide exact correlations with knocking engines.

\section{Extensions to practical hydrocarbon fuels}

These heptane isomer reaction mechanisms not only provide computational models for alkane fuels of widely different reactivity, they also include submechanisms of $C_{1}-C_{6}$ paraffins, $C_{2}-C_{7}$ olefins, oxygenated species, and many others. Practical transportation and other systems use complex mixtures of chemical components, including gasoline, diesel fuel, and aviation or jet fuel. Definition of a computational fuel component mixture that can adequately simulate these complex fuels usually requires that the mixture contain representative members of each class of species, with corresponding variations in combustion properties. Clearly, all of these species must also have reliable 
kinetic reaction mechanisms, so the present models should enhance the ability to assemble suitable component mixtures for these purposes.

These reaction mechanisms can also provide a demanding testbed against which to compare current and future detailed mechanism generation and reduction techniques. In particular, each isomer has distinctly different high temperature [14] and low temperature kinetic features, and development of reduction methods that can retain those differences will be challenging.

Only the n-heptane kinetic mechanism has been tested thoroughly by comparisons between computed and experimental data from a wide range of reacting environments, thus achieving a "comprehensive" reaction mechanism [18]. Because of the scarcity of such experimental data for the other isomers, uncertainties in important features of their mechanisms are correspondingly greater than for $n$-heptane, and additional experiments will be necessary to refine the mechanisms further. However, the results described here, together with the shock tube simulations described previously, provide an excellent starting point for further development, and it is quite likely that most of the most important kinetic features of their reaction mechanisms have been included with reasonable accuracy for many types of applications.

\section{Acknowledgments}

This work was performed under the auspices of the U.S. Department of Energy by the Lawrence Livermore National Laboratory under contract No. W-7405ENG-48. 
Figure Captions

1. Ignition delay times for 2-methyl pentane and 2-methyl hexane in the RCM. Open symbols represent experimental results for 2-methyl pentane (triangles) and 2-methyl hexane (circles), and filled circles show computed results for 2-methyl hexane.

2. Computed (filled symbols) and experimental (open symbols) ignition delay times for 2,4-dimethyl pentane.

3. Computed (filled symbols) and experimental (open symbols) ignition delay times for 2,2-dimethyl pentane. Filled diamond symbols are computed using the previous kinetic mechanism.

4. Computed ignition delay times for all nine heptane isomers. Fuel name abbreviations are explained in Table 1. 


\section{References}

1. Westbrook, C.K., Proc. Combust. Inst. 28, 1563-1577 (2000).

2 Griffiths, J.F., Halford-Maw, P.A., and Mohamed, C., Combust. Flame 111, 327-337 (1997).

3. Minetti, R., Ribaucour, M., Carlier, M., Fittschen, C., and Sochet, L.R., Combust. Flame 96, 201-211 (1994).

4. Halstead, M.P., Kirsch, L.J., and Quinn, C.P., Combust. Flame $\underline{30}$, 45-60 (1977).

5. Ribaucour, M., Minetti, R., Sochet, L.R., Curran, H.J., Pitz, W.J., and Westbrook, C.K., Proc. Combust. Inst. 28, 1671-1678 (2000).

6. Cox, A., Griffiths, J.F., Mohamed, C., Curran, H.J., Pitz, W.J., and Westbrook, C.K., Proc. Combust. Inst. 26, 2685-2692 (1996).

7. Westbrook, C.K., Curran, H.J., Pitz, W.J., Griffiths, J.F., Mohamed, C., and Wo, S.K., Proc. Combust. Inst. 27, 371-378 (1998).

8 Westbrook, C.K., Pitz, W.J., and Leppard, W.R., Society of Automotive Engineers paper SAE-912314 (1991).

9. Flynn, P.F., Durrett, R.P., Hunter, G.L., zur Loye, A.O., Akinyemi, O.C., Dec, J.E., and Westbrook, C.K., Society of Automotive Engineers paper SAE=9901-0509 (1999).

10. Lovell, W.G., Ind. Eng. Chem. 40, 2388 (1949).

11. Curran, H.J., Gaffuri, P., Pitz, W.J., Westbrook, C.K., and Leppard, W.R., Proc. Combust. Inst. 26, 2669-2677 (1996).

12. Curran, H. J., Gaffuri, P., Pitz, W. J., Westbrook, C. K., and Leppard, W. R. SAE Transactions, Section 4, Volume 104, pp. 1184-1195 (1995).

13. Wilk, R. D., Pitz, W. J., Westbrook, C. K., Addagarla, S., Miller, D. L., Cernansky, N. P., and Green, R. M., Proc. Combust. Inst. 23: 1047-1053 (1990).

14. Westbrook, C.K., Pitz, W.J., Curran, H.J., Boercker, J., and Kunrath, E., Int. J. Chem. Kinet. 33, 868-877 (2001).

15. Griffiths, J.F., Rose, D.J., Schreiber, M., Meyer, J., and Knoche, K.F., Proc. Mech. I. Eng. 448, 29 (1992). 
16. Pollard, R.T., Comprehensive Chemical Kinetics, Vol. 17 (C.H. Bamford and C.F.H. Tipper, eds.), Elsevier, New York, 1977.

17. Walker, R.W., and Morley, C., Comprehensive Chemical Kinetics, Vol. 35 (M. J. Pilling, ed.), Elsevier, New York, 1997.

18. Curran, H.J., Gaffuri, P., Pitz, W.J., and Westbrook, C.K., Combust. Flame 114, 149-177 (1998).

19. Curran, H.J., Gaffuri, P., Pitz, W.J., and Westbrook, C.K., Combust. Flame, in press (2002).

20. Baldwin, R.R., Hisham, M.W.M., and Walker, R.W., J. Chem. Soc. Faraday Trans. 1, $\underline{78}, 1615$ (1982).

21. Hughes, K.J., Halford-Maw, P.A., Lightfoot, P.D., Turanyi, T., and Pilling, M.J., Proc. Combust. Inst. 24: 645-652 (1992).

22. Chen, C.J., and Bozzelli, J.W., J. Phys. Chem. A. 103, 9731-9769 (1999).

23. http://www-cms.IInl.gov/combustion/combustion_home.html

24. Lund, C.M., LLNL report UCRL-52504, 1978.

25. M. Ribaucour, unpublished.

26. Dean, A.M., and Bozzelli, J.W., in Gas-Phase Combustion Chemistry, 2nd ed. (W.C. Gardiner, Jr., ed.), Springer-Verlag, New York, 1999. 
RON Short fuel name Chemical name

$\begin{array}{lllll}\text { C C C C C C C } & 0 & \text { nc7 } & \text { n-heptane }\end{array}$

$\begin{array}{cccc}\text { C C C C C C } & 42 & 2 C 7 & \text { 2-methyl hexane } \\ \text { C } & & & \\ \text { C C C C C } & 52 & 3 C 7 & \text { 3-methyl hexane }\end{array}$

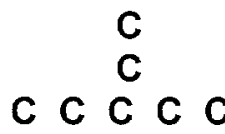

3eth C7 3-ethyl pentane

c c ${ }_{C}^{\mathrm{C}} \mathrm{C}$

81

$33 \mathrm{C} 7$

3,3-dimethyl pentane

$\begin{array}{lllll}\mathrm{C} & \stackrel{\mathrm{C}}{\mathrm{C}} & \mathrm{C} & \stackrel{\mathrm{C}}{\mathrm{C}}\end{array}$

83

$24 C 7$

2,4-dimethyl pentane

C $\stackrel{C}{C} \stackrel{C}{C}$ C

91

$23 \mathrm{C7}$

2,3-dimethyl pentane

$\mathrm{C}_{\mathrm{C}}^{\mathrm{C}} \mathrm{C} \mathrm{c} \mathrm{C}$

93

$22 \mathrm{C7}$

2,2-dimethyl pentane

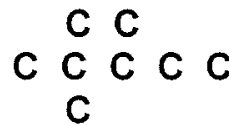

112

$223 \mathrm{C7}$

2,2,3-trimethyl butane

Table 1 Isomers of heptane, with their values of Research Octane Number (RON), abbreviated name for Fig. 4 and chemical name 


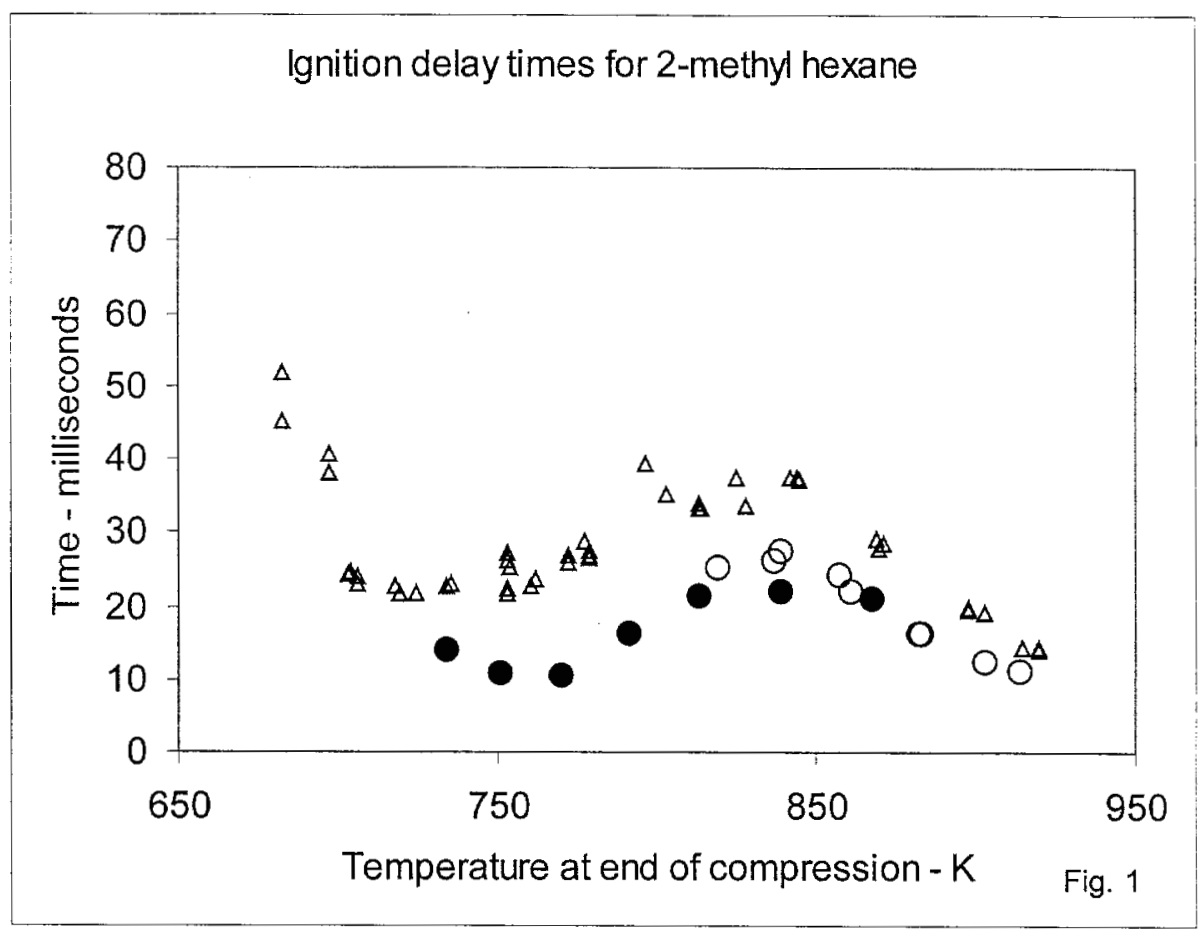




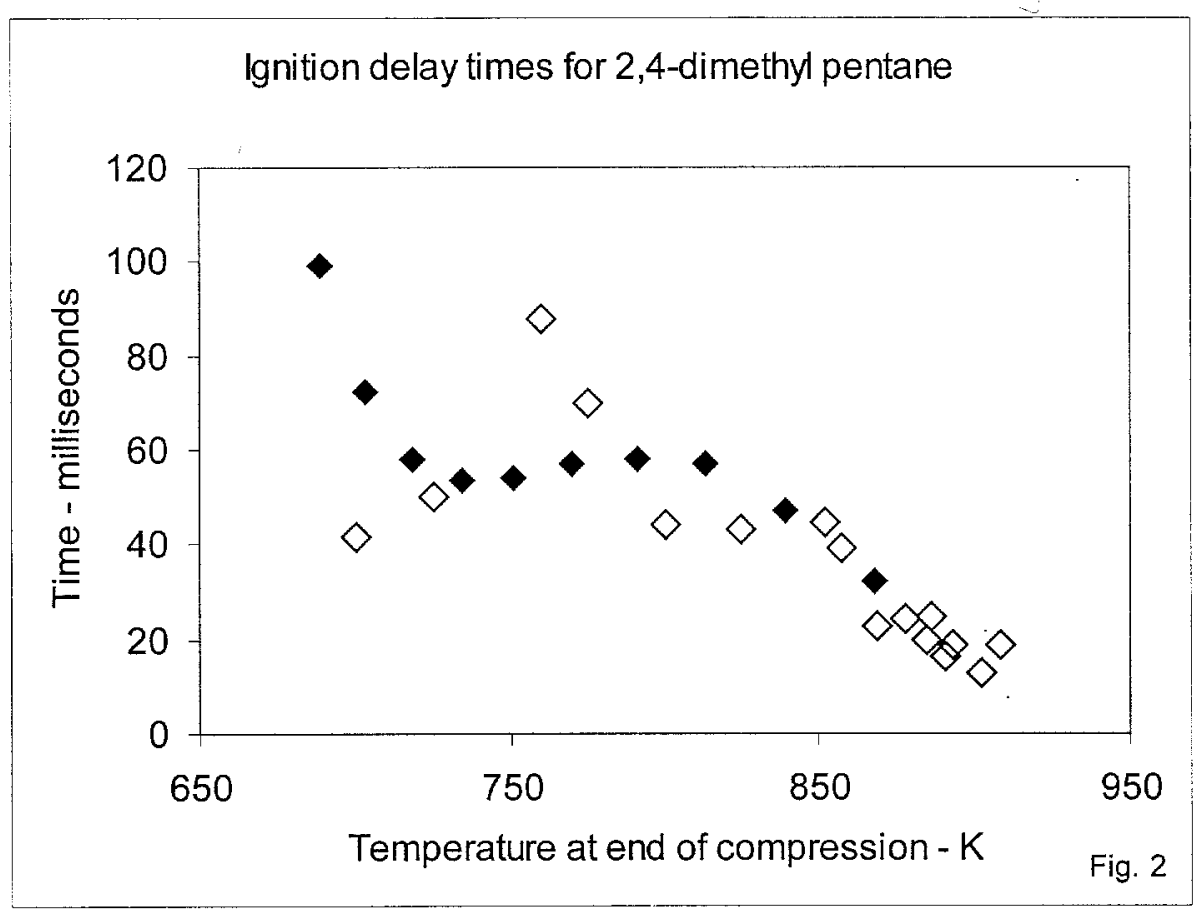




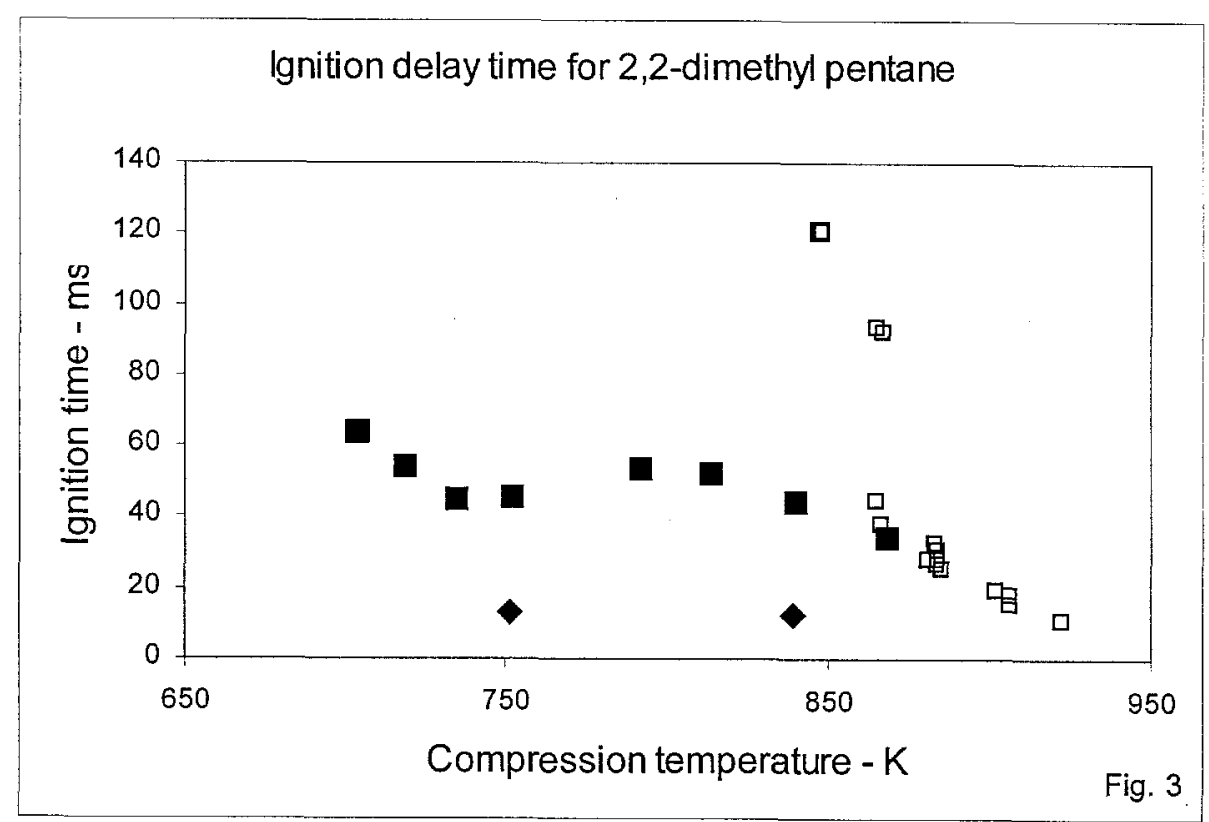




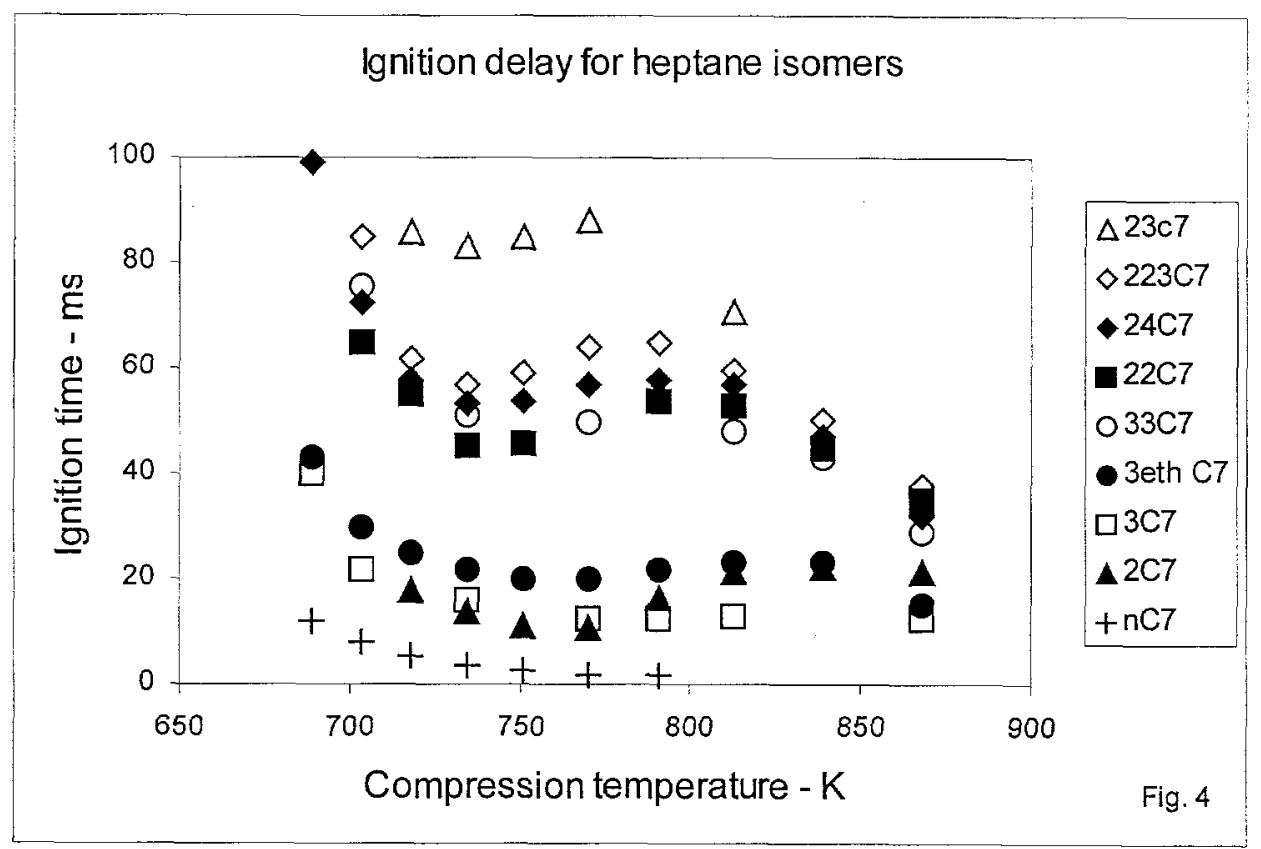

